\title{
New ideotypes of oil \& protein crops
}

\author{
Patrick Vincourt ${ }^{*}$, \\ National Institute for Agronomic Research (INRA), Toulouse, France
}

Received 31 October 2018 - Accepted 6 November 2018

Fifty years ago, Donald (1968) introduced the concept of "ideotype" in plant breeding with the following sentence: "The term "ideotype", literally "a form denoting an idea", is here proposed for biological models. In its broadest sense, an ideotype is a biological model which is expected to perform or behave in a predictable manner within a defined environment." While he mainly argued his advocacy on wheat, this concept became very familiar from the beginning of the 1970's in the whole plant breeding domain. It is worth noting that modeling the crop functioning was already present behind the Donald's "ideotype".

The first plant ideotypes were defined with the primary objective to increase the yield potential. For example, the wheat ideotype was designed as having erect leaves to optimize the photosynthesis. However, Donald wrote "Thus the use of varieties with erect foliage will involve greater attention to weed control by methods other than by competition from the crop". This shows that the ideotype is highly context dependent. Indeed, today, the ability for a crop to compete with weeds became a breeding target (Van der Meulen and Chauhan, 2017), due to the rejection of chemical herbicides by the public opinion.

In this Special Issue, the term "ideotype" does not focus on yield or photosynthesis optimization through plant architecture, but on the complex profile defined by the wide and more and more diverse set of the breeding targets, including quality traits. The purpose is neither to draw what should be the ideotype of oil and protein crops. Rather, we aimed at explaining some aspects or approaches to take into account regarding the definition of an ideotype.

As a scientific introduction to the topic, Gauffreteau (2018) is explaining how the concept of ideotype could help in building a framework to design a target -actually, a multidimensional target, either phenotypic or genotypicwith the different stakeholders.

The world market for agricultural products has been becoming both global and highly segmented. Thus, while a single type of cellular phone, even under different trademarks, is produced and marketed all over the world, there is an increasing diversity of crop productions to fulfill the needs - or

\footnotetext{
*Correspondence: patrick. vincourt@orange.fr

${ }^{a}$ Retired from National Institute for Agronomic Research (INRA), Toulouse, France.
}

the requirements, which are not obviously the same - of the population and the industry. Tonin et al. (2018) discussed how the three main actors (consumers, farmers, food industry) are contributing to define a multivariate ideotype, particularly for the harvest quality traits.

Among the researchers involved in plant breeding, Donald (1968) was probably the first to invoke "model plant" as a tool to trace a road aiming to solve the questions raised by plant biology, physiology and breeding. It's one of the reasons why, in this Special Issue, Jasinski et al. (2018) were solicited to explain how the use of Arabidopsis thaliana model plant is of interest to explore by which way the alternative resource allocation between oil and protein could be managed by genetic design.

As it has been already the case, from time to time all along the past fifty years in Europe, more and more interest is devoted to leguminous crops. Oil crops like oilseed rape and sunflower can provide protein meal for animal feeding. However, these crops are (mostly for oilseed rape) "chemical nitrogen dependent", and with some dietary limitations for animal feeding when compared to imported (and mostly GMO) soybeans. Increasing the knowledge on the interaction of leguminous plants with the agronomic environment could benefit to projects aiming at limiting greenhouse gas (GHG) emissions in increasing the part of plant protein in human consumption (Springmann et al., 2018). G. Mendel opened the way a couple of centuries ago: Pisum sativum is certainly a good model in Western Europe to decipher how it works. Burstin et al. (2018) provides explanations regarding the PeaMUST project, which aims to solve some of these challenges.

More as a comment than as a scientific demonstration, we also asked here (Vincourt and Carolo, 2018) whether the Participatory Plant Breeding approaches are modifying the definition and/or the conceptual and practical content of the ideotype. It seemed to us of interest to decipher how, in this field, the interaction between science and society became of upmost importance.

Not all the topics of interest regarding the ideotypes in plant breeding found the opportunity to be discussed in this Issue. For example, it would have been interesting to get the point of view of expert and regulatory organizations such as GEVES in France (https://www.geves.fr/about-us/, French Ministry of Agriculture). Indeed, GEVES is clearly involved, 
including with scientists in plant biology, breeding and agronomy as well as farmers representatives, in the definition of ideotypes for agriculture. Probably because the ideotype is considered as a marketing secret by private seed companies, we did not succeed to include the approach of these stakeholders. Also, because modeling the crop growth and functioning is becoming an accessible dream in the big data world (ex.: Mangin et al., 2017), and because Donald (1968) clearly predicted that modeling could be the way to design future crops, we would have preferred to get the possibility to enhance this way. We however hope that this Issue will provide insights regarding ideotypes: reasoning on "biodiversity" of the plant breeding targets.

\section{References}

Burstin J, Rameau C, Bourion V, Tayeh N. 2018. The PeaMUST project: defining ideotypes for the pea crop development. OCL 25 (6): D604.

Donald MC. 1968. The breeding of crop ideotypes. Euphytica 17: 385-403.
Gauffreteau A. 2018. Using ideotypes to support selection and recommendation of varieties. OCL 25(6): D602.

Jasinski S, Chardon F, Nesi N, Lécureuil A, Guerche P. 2018. Improving seed oil and protein content in Brassicaceae: some new genetic insights from Arabidopsis thaliana. OCL 25(6): D603.

Mangin B, Casadebaig P, Cadic E, et al. (2017) Genetic control of plasticity of oil yield for combined abiotic stresses using a joint approach of crop modelling and genome-wide association. Plant, Cell Environ 40: 2276-2291.

Tonin P, Gosselet N, Halle E, Henrion M. 2018. Ideal oil and protein crops - what are users expectations ideotypes, from the farmer to the consumer? OCL 25(6): D605.

Springmann M, Clark M, Mason-D'Croz D, et al. 2018. Options for keeping the food system within environmental limits. Nature 562: 519-525.

Van der Meulen A, Chauhan BS. 2017. A review of weed management in wheat using crop competition. Crop Prot 95: 38-44.

Vincourt P, Carolo P. 2018. Alternative breeding processes: at which extent participatory breeding should modify the concept of ideotypes in plant breeding? OCL 25(6): D606.

Cite this article as: Vincourt P. 2018. New ideotypes of oil \& protein crops. OCL 25(6): D601. 